\title{
The Impact Analysis of Water Body Landscape Pattern on Urban Heat Island: A Case Study of Wuhan City
}

\author{
Bohan Yang, Fen Meng, Xinli Ke, and Caixue Ma \\ College of Land Management, Huazhong Agricultural University, Wuhan 430079, China \\ Correspondence should be addressed to Xinli Ke; kexl@igsnrr.ac.cn
}

Received 17 September 2014; Revised 4 March 2015; Accepted 5 March 2015

Academic Editor: Hongbo Su

Copyright ( 2015 Bohan Yang et al. This is an open access article distributed under the Creative Commons Attribution License, which permits unrestricted use, distribution, and reproduction in any medium, provided the original work is properly cited.

\begin{abstract}
Based on the LST and the landscape metrics of water body with remote sensing technique and spatial analysis, the relationship between the mean LST and the attributes of water body was revealed via Pearson's correlation analysis and multiple stepwise regression analysis. Result showed that, in 32 class-based metrics we selected, the proportion of water body, average water body size, the isolation and fragmentation of water body, and other eight metrics have high correlation with the LST. As a resultant force, the quantity, shape, and spatial distribution of water body affect the forming of temperature. We found that the quantity and spatial pattern of city water body could be allocated reasonably to maximize its cooling effect.
\end{abstract}

\section{Introduction}

With the rapid development of urbanization since industrial revolution, land use and land cover (LULC) of the earth has changed dramatically because of human activities and natural disasters. At the same time, LULC not only changed the land surface condition, but also reduced the stability of the earth surface ecosystem. As a result, LULC has affected the climate change directly and indirectly [1] and hence has become more and more important study area for environmental researchers [2-4].

One relative mature research is the study of the relationship between LULC and urban heat island (UHI) [3, 4]. Studies have proved that the urban built-up land has positive influence on UHI [5], while green landscape has negative influence on UHI [3]. In addition, water body is another land use type with negative influence $[6,7]$ as the water bodies in city achieve cooling effect by transpiration and heat exchange with the surrounding environment. Compared with the studies of built-up, green landscape land use types, the research on urban water body is relatively less at present. There are three aspects in this research: (1) the relationship between water body and land surface temperature; the temperature of water is lower than other kinds of land uses [7]; (2) the impact of spatial characteristics (e.g., shape) on UHI [8]; (3) the configuration of water body, and its relationship with UHI [9].
The land surface temperature (LST), as one important indicator of the UHI [1], has been used in many researches to represent climate effects. This paper studies the relationship between the land surface temperature and the water body from the view of landscape pattern.

Wuhan, the capital of Hubei province, in central China, is famous for the title of "one of four furnaces in China." And it has another name: "the city of hundreds lakes", whose water area covers around $25 \%$ of the territory and the coverage of water area ranks first in the whole country. In recent years, Wuhan city has experienced rapid urbanization and economic development. As a result, many urban water bodies in Wuhan city have been disappeared because of the pressure to gain extra land profit in the process of urban development [10]. At the same time, the land use/cover change has a great effect on its local climate. Therefore, Wuhan city is chosen as the case area to estimate the relationship between LST and the water pattern from the view of landscape ecology.

Based on existing research, this paper used the Landsat Thematic Mapper (TM) data to retrieve LST and land use/ cover for water. Then, considering the number of samples and computational burden, Wuhan city was divided into 736 sample areas whose size is $3000 \mathrm{~m} * 3000 \mathrm{~m}$. Then the landscape metrics of water and the mean LST of each sample area were calculated by using ArcGIS 10.0. With the help of 




FIGURE 1: Wuhan city, the research area.

statistical analysis theory and methods, Pearson's correlation coefficients were used to determine the effect of the spatial structure of water on the LST. Finally, the computed experimental samples could be fitted to multiple linear regression model by stepwise regressions.

\section{Study Area and Data Sources}

2.1. Study Area. Wuhan city is situated in central China and located between $113^{\circ} 41^{\prime}-115^{\circ} 05^{\prime} \mathrm{E}$ and $29^{\circ} 58^{\prime}-31^{\circ} 22^{\prime} \mathrm{N}$, shown in Figure 1. Wuhan is located at a subtropical humid monsoon climate zone, with an annual mean precipitation about $1096.1 \mathrm{~mm}$. The average annual temperature ranges from $15.8^{\circ} \mathrm{C}$ to $17.5^{\circ} \mathrm{C}$, and sometimes in summer the maximum temperature can soar to $40^{\circ} \mathrm{C}$.

The total territorial area of Wuhan is about $8494.41 \mathrm{~km}^{2}$, and the water area is about one-fourth of the city's total area. The famous rivers and lakes in Wuhan city are Yangtze River, Han River, East Lake, South Lake, and so on. These rivers/lakes mentioned above, together with other water bodies of Wuhan, are scattered and distributed in the study area. And they have a big influence on humidity, purifying atmosphere of Wuhan climate.

Wuhan's economy strength has grown rapidly, and levels of the industrialization and urbanization were improved as well. By the end of 2005, the resident population of Wuhan city was 8.58 million, and the annual GDP per capita reached 26238 Yuan.

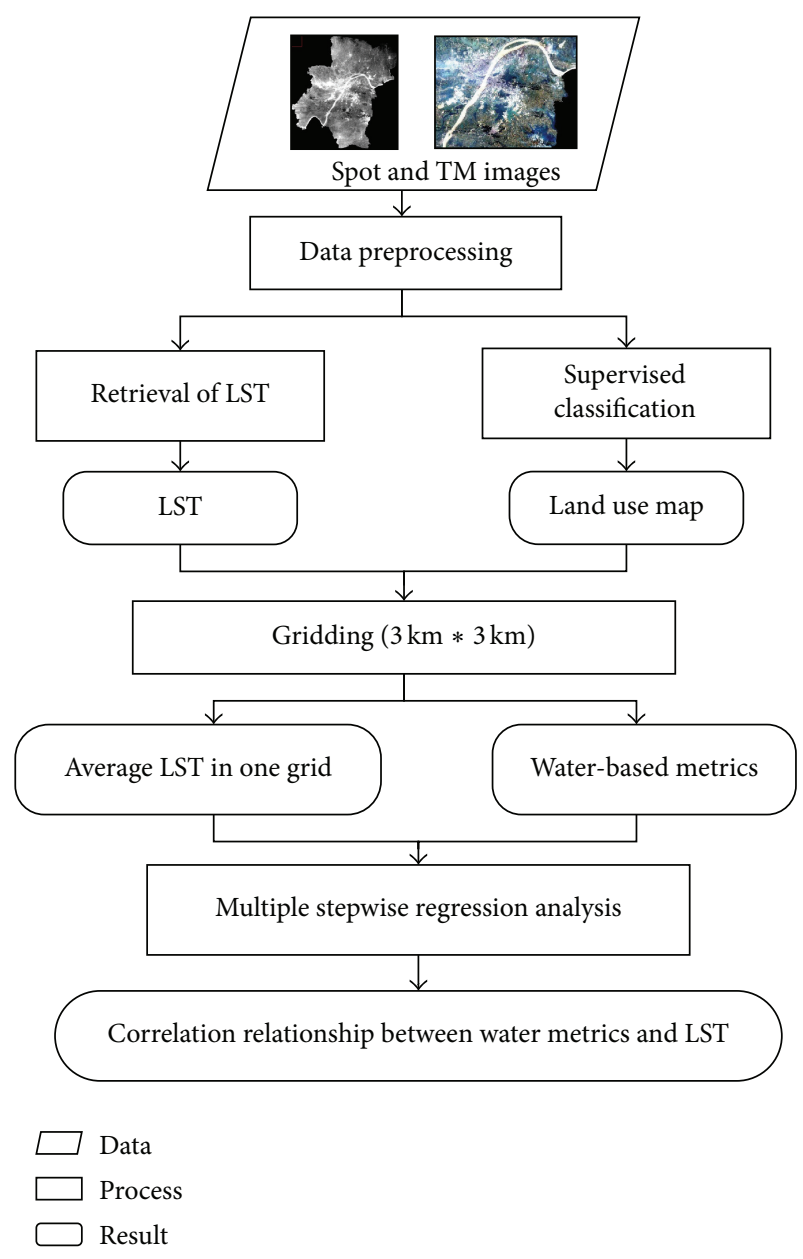

FIGURE 2: Research framework of landscape metrics of water on land surface temperature.

2.2. Data Sources. This paper utilized three types of data: social-economy statistical data, Wuhan land use data, and LST data derived from remote sensing images. (1) The socialeconomy statistical data, such as population/annual GDP per capita in this paper, came from Wuhan Statistical Yearbook and Wuhan City Water Resources Bulletin. (2) A Landsat 5 TM imagery on September 11, 2005, (patch/row: 122/39) was selected to quantitatively measure LST and the situation of LULC. All bands of TM images except band 6 have a spatial resolution of $30 \mathrm{~m}$, while band 6 (thermal infrared band) has a spatial resolution of $60 \mathrm{~m}$. Before getting LULC information from the raw image, image preprocessing such as geometric rectification, relative radiometric correction, and atmospheric correction was completed. In addition, a Spot image on December 15, 2005, with a spatial resolution of $4 \mathrm{~m}$ was used to verify results of supervised classification in the study area.

\section{Methods and Models}

3.1. Research Framework. The basic idea of analysis for the impacts of landscape metrics of water on land surface temperature is illustrated in Figure 2. Based on the Landsat 


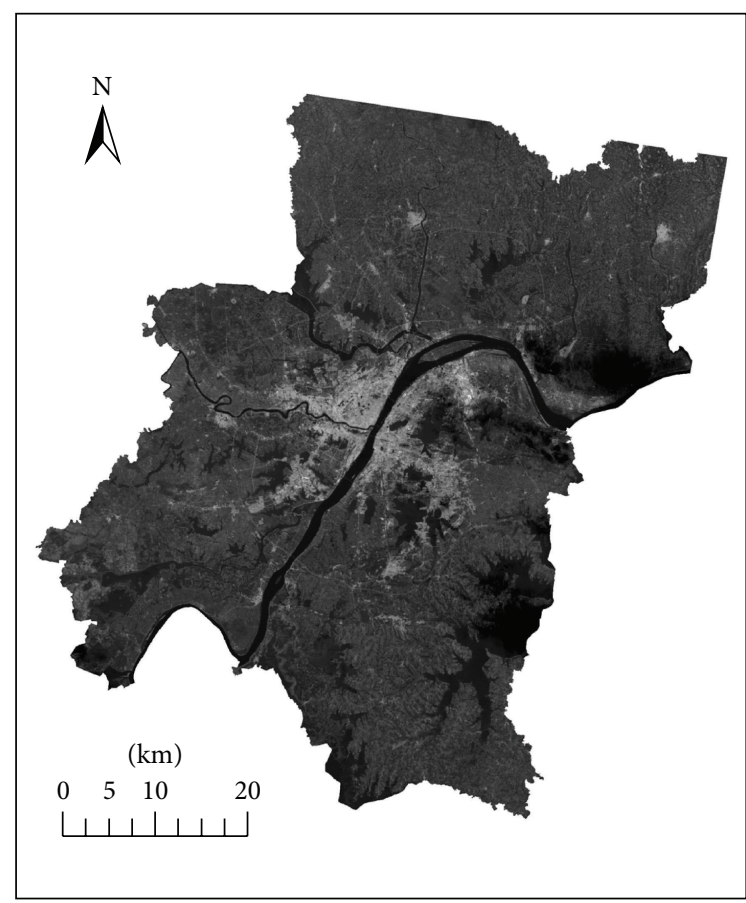

Temperature $\left({ }^{\circ} \mathrm{C}\right)$



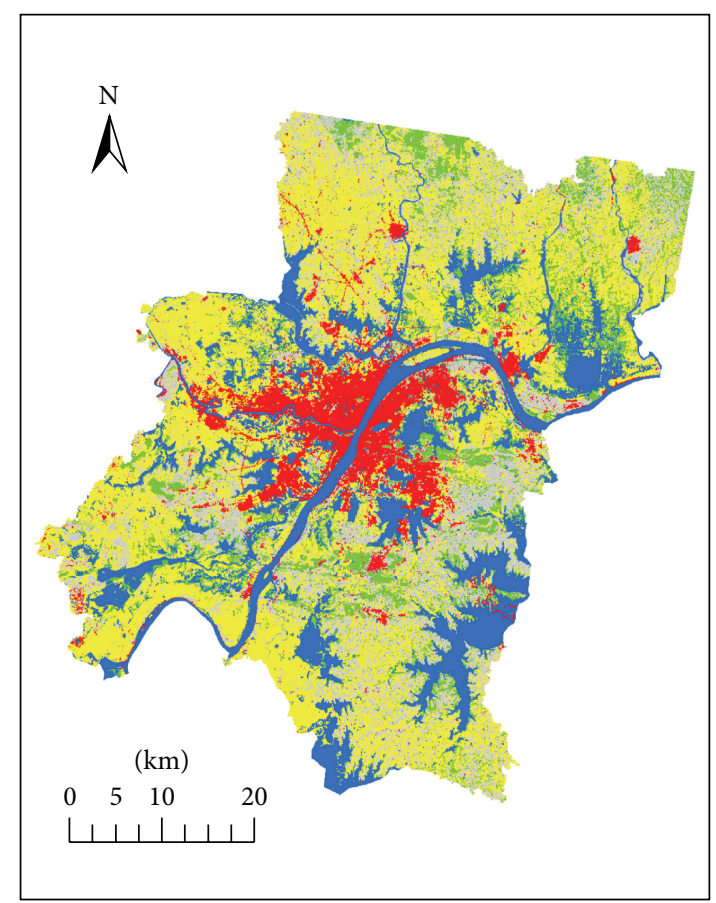

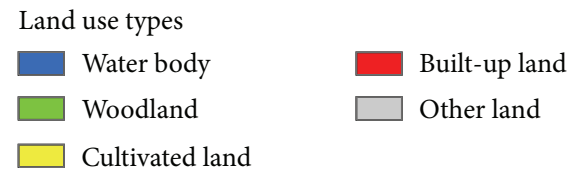

(b)

FIgURE 3: Land surface temperature (a) and land use map (b) in Wuhan city.

5 TM imagery, the land use information was extracted by the method of supervised classification, and the LST was retrieved by using the single-channel algorithm. Then considering number of statistical samples and the computational burden, Wuhan was divided into 736 sample regions. The mean LST and landscape metrics of water in each sample region as sample data would be used to do Pearson's correlation analysis and multiple stepwise regression analysis. By comparing relationship between the landscape metrics of water and the LST, it is meaningful to reveal the impacts of the spatial structure of water on LST, which can help improving urban environment through rational allocation of water resources.

3.2. Acquisition of Land Use Map. In order to calculate landscape metrics of water, a land cover classification is necessary to obtain the land use map in study area. In this paper, five land use classes were established: urban, forest, cropland, bare land, and water. It should be pointed out that water in here mainly includes rivers, lakes, and ponds. There are three steps to derive land use map. First, region of interest (ROI) was selected on the true color image, which was produced by combining bands 5, 4, and 3 of the TM images. They were used as training areas after passing separable test. Second, neural net classification was employed to perform the classification. Third, for each land category, at least 60 samples were selected randomly to check the accuracy of the classified maps by using confusion matrices. In addition, the true ROI was identified on the Spot image used as ground surveys in accuracy assessment. The overall accuracy is approximately $80 \%$, and the overall kappa statistics value nearly reached 0.8 , which met the recommended value. Fourthly, a $3 * 3$ moving window in clump process was used to do postclassification process, which can eliminate the unnecessary image noises from visual interpretation. After completing these above steps, the land use map was obtained as shown in Figure 3(b).

3.3. Retrieval of LST. In order to acquire the LST of Wuhan city, the brightness temperature should be derived first. A method composed by three equations was proposed by Qin et al. (2001) to derive brightness temperature from TM images [11].

The first equation can convert digital number of band 6 into radiation luminance $\left(L_{\mathrm{TM} 6}, \mathrm{~m} \times \mathrm{W} \times \mathrm{cm}^{-2} \times \mathrm{sr}^{-1}\right)$ as follows:

$$
L_{\mathrm{TM} 6}=\frac{\mathrm{DN} \times\left(L_{\max }-L_{\min }\right)}{255}+L_{\min } \text {, }
$$

where $\mathrm{DN}$ is the digital number of TM image. $L_{\max }$ and $L_{\min }$ represent the maximum and minimum radiation luminance corresponding to the $\mathrm{DN}_{\max }(255)$ and $\mathrm{DN}_{\text {min }}(0)$. According 


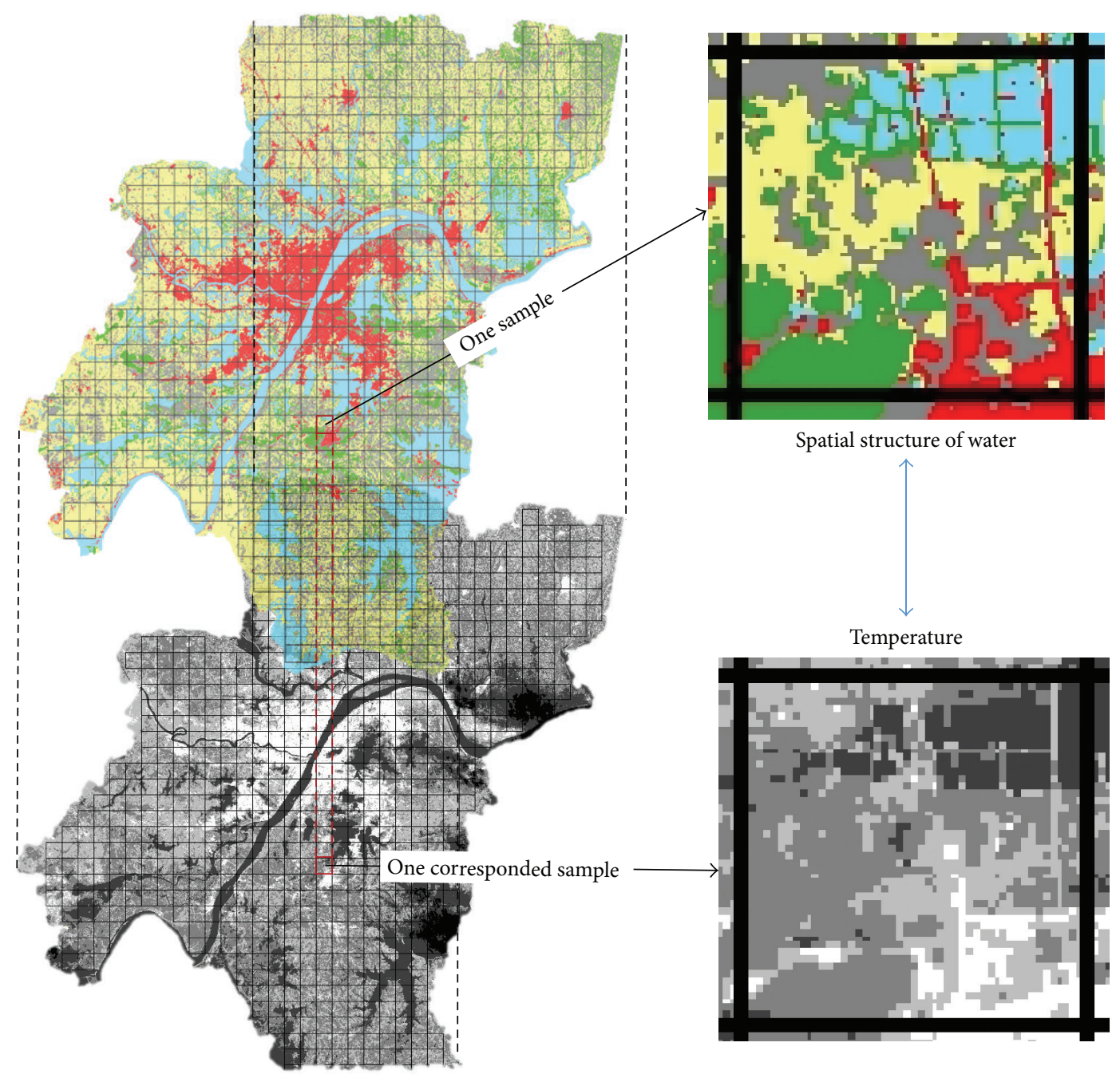

FIGURE 4: Water spatial structure and its corresponding mean temperature in sample areas.

to $\mathrm{Li}$ [12], the $L_{\max }$ is $1.896 \mathrm{~m} \times \mathrm{W} \times \mathrm{cm}^{-2} \times \mathrm{sr}^{-1} \times \mu \mathrm{m}^{-1}$ and $L_{\text {min }}$ is $0.1534 \mathrm{~m} \times \mathrm{W} \times \mathrm{cm}^{-2} \times \mathrm{sr}^{-1} \times \mu \mathrm{m}^{-1}$.

Then brightness temperature can be derived by two equations as follows:

$$
\begin{gathered}
L_{\lambda}=\frac{L_{\mathrm{TM} 6}}{b}, \\
T=\frac{k_{2}}{\ln \left(k_{1} / L_{\lambda}+1\right)},
\end{gathered}
$$

where $b$ is $1.239 \mu \mathrm{m}$ and represents the effective spectral range; $K 1=60.766 \mathrm{~m} \times \mathrm{W} \times \mathrm{cm}^{-2} \times \mathrm{sr}^{-1} \times \mu \mathrm{m}^{-1}$ and $K 2=$ $1260.56 \mathrm{~K}$, and they are prelaunch calibration constants of Landsat TM5.

The brightness temperature obtained above just represents blackbody temperature. However, the blackbody is not existent in the real world. So it is necessary to convert the brightness temperature into LST by using the following formula [13]:

$$
T_{S}=\frac{T}{1+(\lambda * T / \rho) \ln \varepsilon},
$$

where $T_{s}$ represents the LST, $T$ represents brightness temperature, and $\lambda$ is the effective wavelength whose value is $11.5 \mu \mathrm{m} ; \rho=h c / \sigma=1.438 * 10^{-2} \mathrm{mk}$; Boltzmann constant $\sigma=1.38 * 10^{-23} \mathrm{~J} / \mathrm{K}$; Planck constant $h=6.626 * 10^{-34} \mathrm{~J} * \mathrm{~S}$; speed of light $c=2.998 * 10^{8} \mathrm{~m} / \mathrm{s}$ [14]. As emissivity is difficult to obtain, this paper uses Van's empirical formula [15]: when $\mathrm{NDVI} \leq 0.157, \varepsilon=0.923$; when $0.157<\mathrm{NDVI}<0.727$, $\varepsilon=1.0094+0.047 \ln (\mathrm{NDVI})$, and the emissivity of water is 0.9925 .

After finishing these above steps, the LST image was retrieved, shown in Figure 3(a).

3.4. Calculation of Spatial Structure of Water Body by Using Landscape Metrics. From the land use map of Wuhan city, it can be intuitively identified that water body is evenly distributed in the whole study area. Unlike other metropolis in China, such as Beijing and Shanghai, the correlation between mean LST and water-based landscape metric is more significant in Wuhan because of the large quantity and special spatial structure of water body in study area [9], as it shown in Figure 4. 
As we all know, landscape metrics are often used for quantitative spatial model building in biological, habitat, and landscape ecological contexts [16]. And they are used to analyze and characterize urban land use and structure types [17]. In this paper, 32 class-based metrics' landscape was used for quantitative expression of the spatial structure of water body.

Considering the relatively low time resolution of TM images, it is not convenient to get a series of sample data in the view of time, and the sample data would be chosen in space. Wuhan was divided into 736 sample regions whose size is $3000 \mathrm{~m} * 3000 \mathrm{~m}$ (the value is determined by several experiments). The mean LST of each sample region was calculated by zonal statistics in ArcGIS 10.0 and the value of Moran's I was acquired to measure the spatial autocorrelation of the mean LST. Then the landscape metrics of water body were got using Patch Analyst 5. Patch Analyst 5 is an extension to ArcGIS system that can facilitate the spatial analysis of landscape patches and is used for spatial pattern analysis.

Then Pearson's correlation coefficients between the landscape metrics and mean LST were calculated. It is a significance test between spatial structure of water body and the mean LST.

Stepwise multiple regression analysis was designed to find the most parsimonious set of predictors which are most effective in predicting the dependent variable [18]. Analyses were performed using IBM SPSS Statistics.

\section{Results and Discussion}

4.1. The Land Use Types and Their Corresponding Mean LST. In this paper, in order to study the land surface temperature relationships of different land use types, the mean temperatures of different land use types were calculated by averaging all corresponding pixel values (Table 1).

The results shown in Table 1 suggested that the built-up area is corresponding to relatively high temperature, while the water body with lowest temperature may affect the LST, which will be considered as potential mitigating factors. Because the urban underlying surface is made up of different land use types, it is reasonable to analyze the relationship between land use and LST, through considering other land use types as potential factors.

\subsection{Relationship between the LST and Landscape of Water} Body. The mean temperature of each sample area is shown in Figure 5, and the value of Moran's I is 0.5969. Moran's I is a measure of spatial autocorrelation. Therefore, it was found that the temperature has a strong spatial autocorrelation. In this paper, we used a covariate to control the autocorrelation of the mean temperature.

Since we select 32 class-based metrics, not every landscape metric has high correlation with temperature. We choose the landscape metrics whose Pearson's correlation coefficient with temperature is higher than 0.4 . The landscape metrics shown in Table 2 are highly related to the landscape metrics of water body.

Through multiple stepwise regression analysis, the most effective landscape metrics in predicting the dependent
TABLE 1: Land use types and their corresponding mean LST in Wuhan city.

\begin{tabular}{lc}
\hline Land use types & Mean LST $\left({ }^{\circ} \mathrm{C}\right)$ \\
\hline Water body & 25.29 \\
Woodland & 28.46 \\
Cultivated land & 28.33 \\
Built-up land & 32.78 \\
Other land & 29.94
\end{tabular}
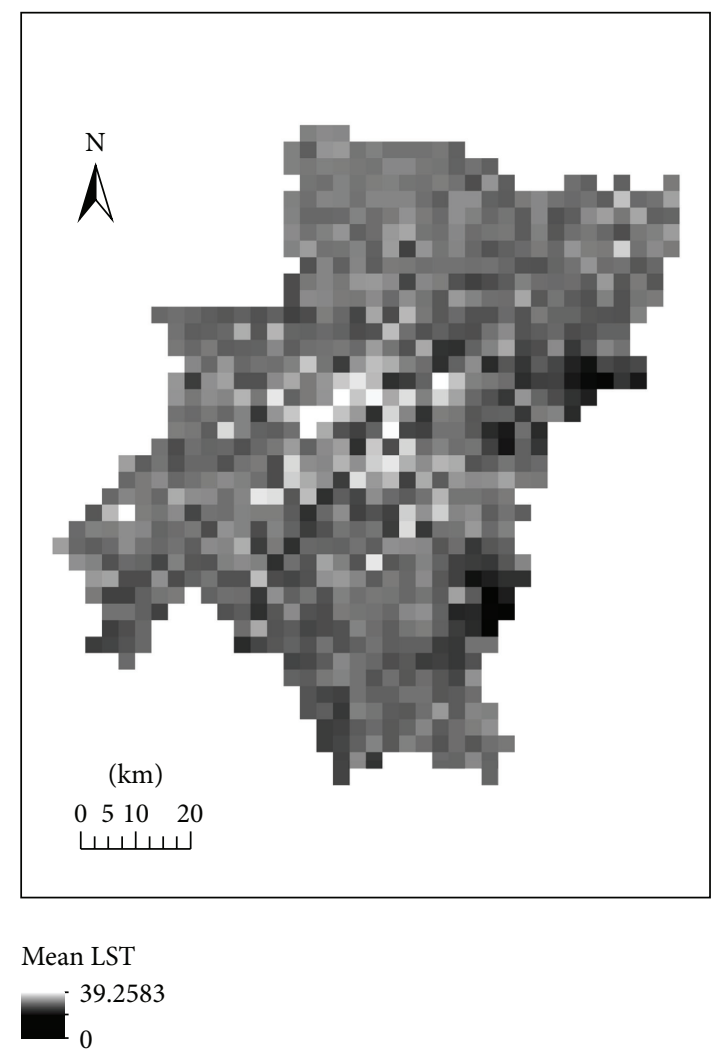

Figure 5: The mean land surface temperature in $3000 \mathrm{~m} * 3000 \mathrm{~m}$ sample region in Wuhan city.

variable (the mean LST) were selected, and multiple linear regression equation was calculated:

$$
\begin{aligned}
y= & 0.704 x_{1}-0.557 x_{2}-0.055 x_{3}+0.128 x_{4}+0.051 x_{5} \\
& +0.064 x_{6}+0.076 x_{7}+0.036 x_{8},
\end{aligned}
$$

where $x_{1}$ represents surrounding temperature accessed from the weight matrix via Generate Spatial Weight Matrix of ArcGIS tools. The threshold of its distance is $6000 \mathrm{~m}$, double of spatial resolution. The weight matrix can be used to explain the impact of surrounding pixels' temperatures on the center pixel. In this study, it can also eliminate the spatial autocorrelation when analyzing the impact of water's factors on temperature. $x_{2}-x_{8}$ represent TCA, MCA, TCAI, CACVI, IJI, MPI, and MNN, respectively. 
TABLE 2: Pearson's correlation coefficient between landscape metrics of water and LST.

\begin{tabular}{lc}
\hline Landscape metrics & Value \\
\hline Class proportion & $-0.604^{* *}$ \\
MPI & $-0.46^{* *}$ \\
CA & $-0.604^{* *}$ \\
MPS & $-0.5^{* *}$ \\
PSSD & $-0.515^{* *}$ \\
TCA & $-0.613^{* *}$ \\
MCA & $-0.436^{* *}$ \\
CASD & $-0.515^{* *}$ \\
TCAI & $-0.408^{* *}$ \\
LPI & $-0.61^{* *}$ \\
MCAI & $-0.474^{* *}$ \\
\hline
\end{tabular}

${ }^{* *}$ Correlation is significant at the 0.01 level.

TABLE 3: Landscape metrics of water and their corresponding meaning, according to the Patch Analyst Help of ArcGIS.

\begin{tabular}{ll}
\hline $\begin{array}{l}\text { Landscape } \\
\text { metrics }\end{array}$ & Meaning \\
\hline $\begin{array}{l}\text { Class } \\
\text { proportion }\end{array}$ & The proportion of class \\
MPI & Measure of the degree of isolation and fragmentation \\
CA & Sum areas of all patches belonging to a given class \\
MPS & Average patch size \\
PSSD & Patch size standard deviation \\
TCA & The total size of disjunct core patches \\
MCA & The average size of disjunct core patches \\
CASD & Measure of variability in core area size \\
TCAI & Measure of amount of core area in the landscape \\
LPI & $\begin{array}{l}\text { The LPI is equal to the percent of the total landscape } \\
\text { that is made up by the largest patch }\end{array}$ \\
MCAI & The average core area per patch \\
IJI & Measure of patch adjacency \\
MNN & Measure of patch isolation \\
\hline
\end{tabular}

The model is significant at the 0.05 level, and the adjusted $R^{2}$ reached 0.814 . All independent variables are significant at 0.05 levels, whose meaning is shown in Table $3[19,20]$.

According to the result, it was found that the LST has spatial autocorrelation with water body. And the surrounding temperature calculated through weight matrix can help reduce the space correlation. The results of Pearson's correlation analysis show that the proportion of water body, average water body size, and the percent of the total landscape have relationship with the mean LST. They are made up by the largest water body patch and the isolation and fragmentation of water body. While the quantity, shape, and spatial distribution of water body affect the forming of temperature as resultant force, the result of multiple stepwise regression analysis reveals how the attributes of water body influence temperature.

\section{Conclusions and Discussions}

Rational allocation of land resources not only maintains the sustainable development of social economy, but also mitigates climate change. This research field has become one of the hottest issues in government and academy society. Despite the fact that Wuhan has abundant surface water resource, the amount of water resources is under severe threat. Meanwhile Wuhan is facing problems caused by urban heat island.

The UHI types can be generally categorized into air temperature UHI and surface UHI $[21,22]$. Air temperature UHIs are generally stronger and exhibit greatest spatial variations at night, whereas the greatest difference in surface UHIs usually occurs during the daytime [21-23]. In this study, we focus on remotely sensed land surface temperature (LST): surface UHI.

Remotely sensed LST records the radiative energy emitted from the ground surface, including building roofs, paved surfaces, vegetation, bare ground, and water [21, 24]. Therefore, the pattern of land cover in urban landscapes may potentially influence LST [21,25]. This study took Wuhan city as the case area and investigated the impact of water landscape pattern on UHI. Based on the mean LST and landscape metrics of water body via remote sensing technique and spatial analysis, the relationship between the mean LST and the attributes of water body was revealed by Pearson's correlation analysis and multiple stepwise regression analysis.

The results showed the following. (1) Compared to other land use types, water body is corresponding to lower LST. (2) In 32 class-based metrics we selected, the proportion of water body, average water body size, the isolation and fragmentation of water body, and other eight metrics have obvious correlation with the LST, whose Pearson's correlation coefficient with temperature is higher than 0.4. Among the 11 metrics, class proportion, CA, TCA, and LPI are of very high correlation with LST. The proportion of water body has a negative correlation with the mean LST. It means that in a fixed region, the lower the ratio of water body, the higher the mean LST. Meanwhile, the average water body size, the percent of the total landscape which is made up by the largest water body patch, and the isolation and fragmentation of water body all have negative correlation with the mean LST. (3) The LST is the result of comprehensive effects of multifactors. The result of multiple stepwise regression analysis indicated that the total size and amount of core water patches have a larger effect on the LST except for the variable of surrounding temperature calculated through weight matrix. The core water patches represent the interior water body with small external influence.

By analyzing the relationship between the LST and the attributes of water body, it was found that the spatial characteristics of water body have impact on LST, thus providing decision support for governments to allocate water resources.

\section{Conflict of Interests}

The authors declare that there is no conflict of interests regarding the publication of this paper. 


\section{Acknowledgments}

This research was financially supported by the National Key Program for Developing Basic Science of China (Grant no. 2010CB950904), the National Science Foundation of China (Grant no. 41101098), the Ministry of Education Research of Social Sciences Youth funded Projects (Grant no. 10YJC790121), and the National Department Public Benefit Research Foundation of the Ministry of Land and Resources of China (Grant no. 201311001-5).

\section{References}

[1] H. Liu and Q. Weng, "Scaling effect on the relationship between landscape pattern and land surface temperature: a case study of Indianapolis, United States," Photogrammetric Engineering and Remote Sensing, vol. 75, no. 3, pp. 291-304, 2009.

[2] W. Zhang and B. Huang, "Land use optimization for a rapidly urbanizing city with regard to local climate change: Shenzhen as a case study," Journal of Urban Planning and Development, vol. 141, no. 1, Article ID 05014007, 2015.

[3] L. Huang, D. Zhao, J. Wang, J. Zhu, and J. Li, "Scale impacts of land cover and vegetation corridors on urban thermal behavior in Nanjing, China," Theoretical and Applied Climatology, vol. 94, no. 3-4, pp. 241-257, 2008.

[4] J. P. Connors, C. S. Galletti, and W. T. L. Chow, "Landscape configuration and urban heat island effects: assessing the relationship between landscape characteristics and land surface temperature in Phoenix, Arizona," Landscape Ecology, vol. 28, no. 2, pp. 271-283, 2013.

[5] X.-L. Chen, H.-M. Zhao, P.-X. Li, and Z.-Y. Yin, "Remote sensing image-based analysis of the relationship between urban heat island and land use/cover changes," Remote Sensing of Environment, vol. 104, no. 2, pp. 133-146, 2006.

[6] Y. Sun, Q. Guo, J. Liu, and R. Wang, "Scale effects on spatially varying relationships between urban landscape patterns and water quality," Environmental Management, vol. 54, no. 2, pp. 272-287, 2014.

[7] E. A. Hathway and S. Sharples, "The interaction of rivers and urban form in mitigating the Urban Heat Island effect: a UK case study," Building and Environment, vol. 58, pp. 14-22, 2012.

[8] W. Yue and L. Xu, "Thermal environment effect of urban water landscape," Acta Ecologica Sinica, vol. 33, no. 6, pp. 1852-1859, 2013.

[9] H. Wu, L.-P. Ye, W.-Z. Shi, and K. C. Clarke, "Assessing the effects of land use spatial structure on urban heat islands using $\mathrm{HJ}-1 \mathrm{~B}$ remote sensing imagery in Wuhan, China," International Journal of Applied Earth Observation and Geoinformation, vol. 32, pp. 67-78, 2014.

[10] Y. Liu, Q. Wang, and H. Chen, "The development, protecting and planning envision of lakes in Wuhan City," Economic Geography, vol. 24, no. 2, pp. 192-196, 2004.

[11] Z.-H. Qin, M.-H. Zhang, A. Karnieli, and P. Berliner, "Monowindow algorithm for retrieving land surface temperature from Landsat TM6 data," Acta Geographica Sinica, vol. 56, no. 4, pp. 456-466, 2001.

[12] J. Li, "Study of relation between land cover condition and temperature based on Landsat/TM data," Remote Sensing Technology and Application, vol. 13, no. 1, pp. 18-28, 1998.

[13] W.-Z. Yue, J.-H. Xu, and L.-H. Xu, "An analysis on ecoenvironmental effect of urban land use based on remote sensing images: a case study of urban thermal environment and NDVI," Acta Ecologica Sinica, vol. 26, no. 5, pp. 1450-1460, 2006.
[14] B. L. Markham and J. L. Barker, "Spectral characterization of the Landsat thematic Mapper sensors," International Journal of Remote Sensing, vol. 6, no. 5, pp. 697-716, 1985.

[15] A. A. Van De Griend and M. Owe, "On the relationship between thermal emissivity and the normalized difference vegetation index for natural surfaces," International Journal of Remote Sensing, vol. 14, no. 6, pp. 1119-1131, 1993.

[16] N. Weber, D. Haase, and U. Franck, "Zooming into temperature conditions in the city of Leipzig: how do urban built and green structures influence earth surface temperatures in the city?" Science of The Total Environment, vol. 496, pp. 289-298, 2014.

[17] R. M. Chefaoui, "Landscape metrics as indicators of coastal morphology: a multi-scale approach," Ecological Indicators, vol. 45, pp. 139-147, 2014.

[18] R. F. Kokaly and R. N. Clark, "Spectroscopic determination of leaf biochemistry using band-depth analysis of absorption features and stepwise multiple linear regression," Remote Sensing of Environment, vol. 67, no. 3, pp. 267-287, 1999.

[19] K. McGarigal and B. J. Marks, FRAGSTATS: Spatial Pattern Analysis Program for Quantifying Landscape Structure, Forest Science Department, Oregon State University, Corvallis, Ore, USA, 1995.

[20] K. H. Riitters, R. V. O’Neill, C. T. Hunsaker et al., "A factor analysis of landscape pattern and structure metrics," Landscape Ecology, vol. 10, no. 1, pp. 23-39, 1995.

[21] A. J. Arnfield, “Two decades of urban climate research: a review of turbulence, exchanges of energy and water, and the urban heat island," International Journal of Climatology, vol. 23, no. 1, pp. 1-26, 2003.

[22] J. E. Nichol, W. Y. Fung, K.-S. Lam, and M. S. Wong, "Urban heat island diagnosis using ASTER satellite images and 'in situ' air temperature," Atmospheric Research, vol. 94, no. 2, pp. 276284, 2009.

[23] C. M. Frey, E. Parlow, R. Vogt, M. Harhash, and M. M. Abdel Wahab, "Flux measurements in Cairo. Part 1: in situ measurements and their applicability for comparison with satellite data," International Journal of Climatology, vol. 31, no. 2, pp. 218-231, 2011.

[24] J. A. Voogt and T. R. Oke, "Thermal remote sensing of urban climates," Remote Sensing of Environment, vol. 86, no. 3, pp. 370384, 2003.

[25] R. T. T. Forman, Land Mosaics: The Ecology of Landscape and Regions, Cambridge University Press, New York, NY, USA, 1995. 



The Scientific World Journal
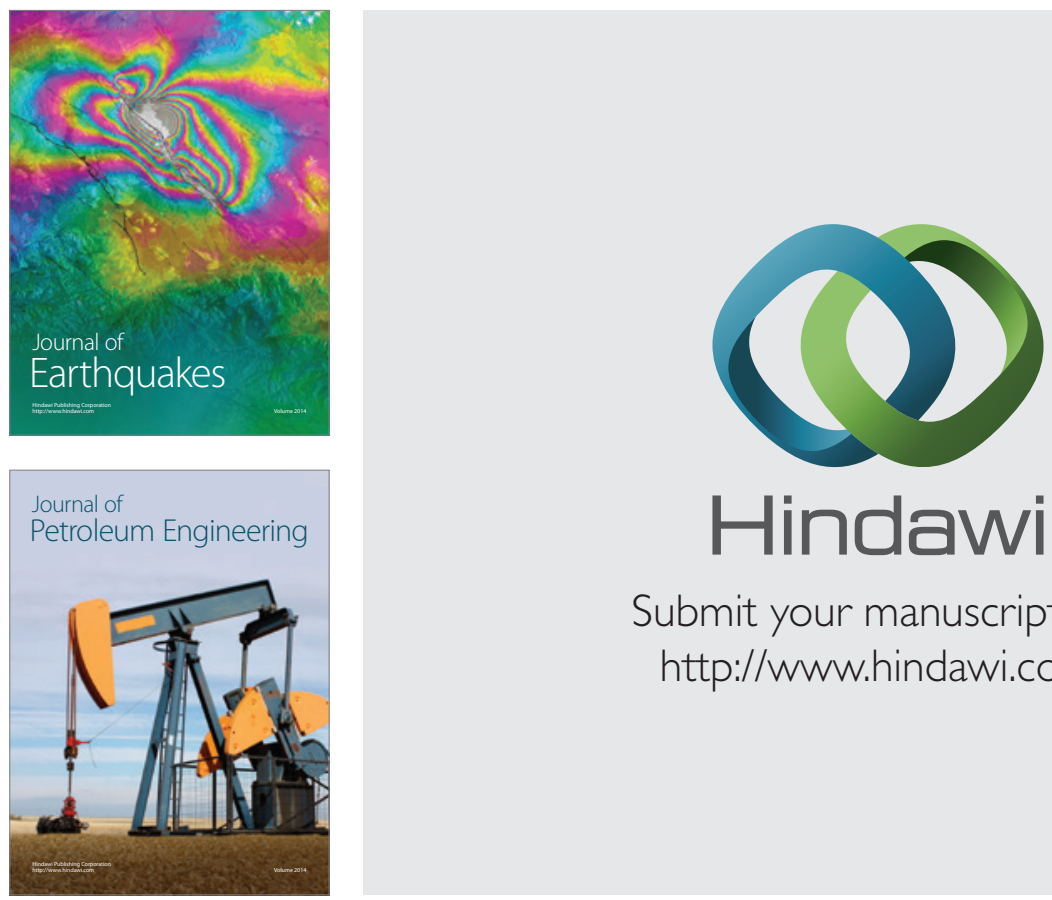

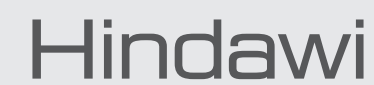

Submit your manuscripts at

http://www.hindawi.com

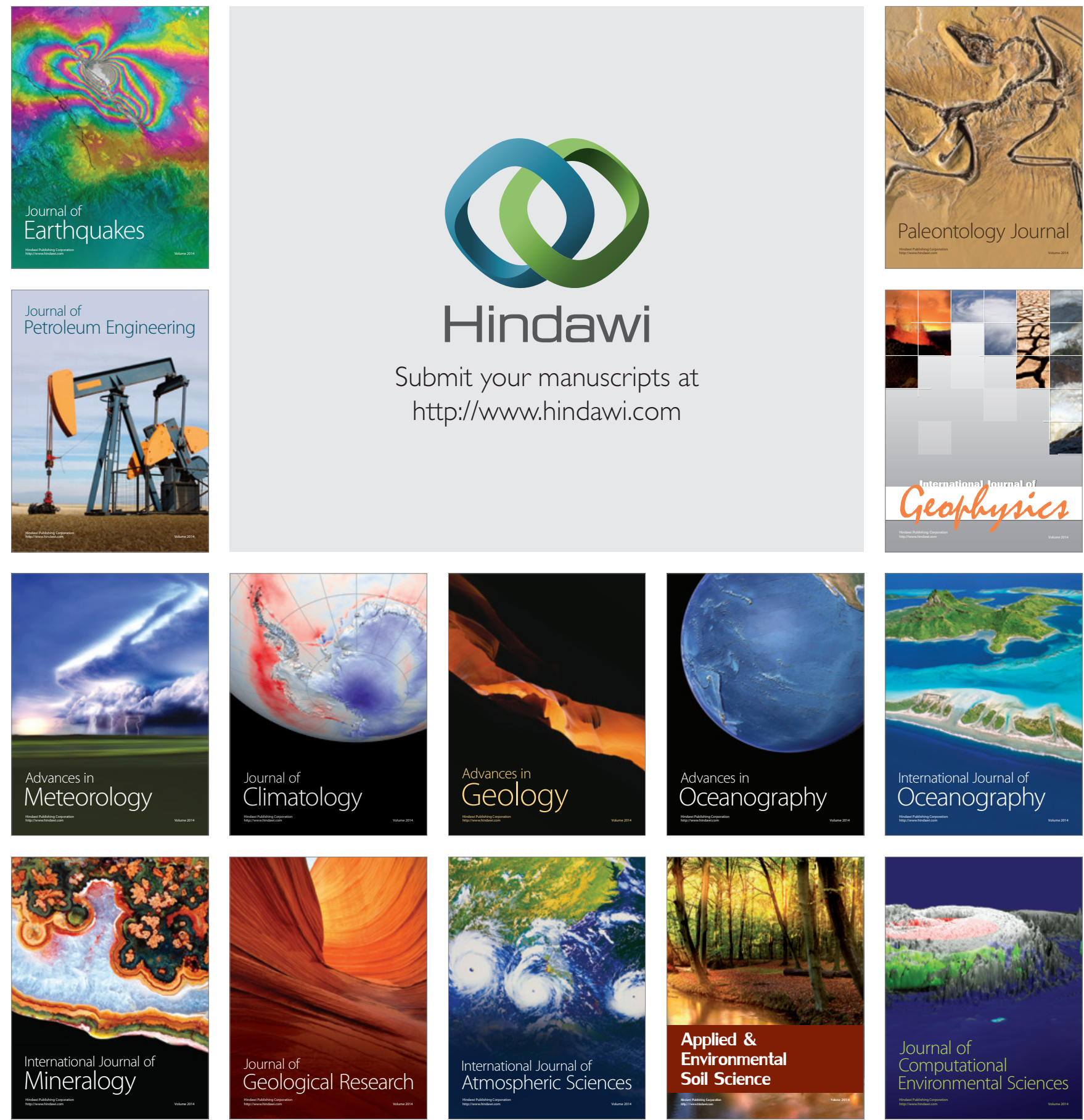